\title{
An evaluation of the impact of a policy-level intervention to address psychosocial risks on organisational action in Italy
}

\author{
Cristina Di Tecco ${ }^{1}$, Aditya Jain ${ }^{2}$, Antonio Valenti ${ }^{1}$, Sergio Iavicoli' ${ }^{1}$,Stavroula Leka ${ }^{3}$ \\ 1. Italian Workers' Compensation Authority (INAIL), Department of Occupational and Environmental \\ Medicine, Epidemiology and Hygiene, Via Fontana Candida 1, Monteporzio Catone, 00040 Rome, Italy \\ 2. Nottingham University Business School, University of Nottingham, Jubilee Campus, Wollaton Road, \\ Nottingham NG8 1BB, UK
}

3. Centre for Organizational Health \& Development, School of Medicine, University of Nottingham, Jubilee Campus, Wollaton Road, Nottingham NG8 1BB, UK

\section{Abstract}

Psychosocial hazards have the potential to cause harm to employee health and negatively affect organisational outcomes. Work-related stress is an outcome of exposure to psychosocial risks that has received broad attention at research and policy level in the last decades. Great awareness raising efforts have been made in the European Union, including at the macro policy level, with several differences and approaches implemented across countries and at national and regional level. However, evaluation of policy-level interventions to address psychosocial risks is still scarce. This paper focuses on Italy as one of the cases where the policy context on psychosocial risks recently changed with the introduction of specific legislation on work-related stress in 2008 (Legislative Decree 81/2008). Using data collected through the European Survey of Enterprises of New and Emerging Risks (ESENER) immediately after (2009) and six years after (2014) the implementation of this new legislation, this paper aims to evaluate the impact of the introduction of this new legislation by exploring differences in the reported level of organisational action as concerns psychosocial risk management. The sample extracted from the ESENER datasets was composed of 2,984 respondents corresponding to 1,501 highest-ranking managers responsible for health and safety at work in 2009 and 1,483 persons who know best about the way safety and health risks are managed at their workplace in 2014. Findings highlighted a decreasing reported concern from the respondents about psychosocial risks over time and a reported improvement in the management of work-related stress prevention. The paper also highlights the use of large scale surveys such as ESENER as an important tool in evaluating health and safety management trends over time in European enterprises.

Keywords: psychosocial risks, policy, regulation, Europe, Italy, ESENER 


\section{Introduction}

Work-related psychosocial factors concern aspects of work organisation, design, management as well as interpersonal relationships in the workplace. Depending on how organisations manage these factors, they can have either positive outcomes (in terms of productivity, work engagement, job satisfaction, etc.) or negative outcomes (in terms of sickness absence, conflicts, human error, turnover, etc.). In the case of the latter, they are referred to as psychosocial hazards since they have the potential to cause harm to employee health and negatively affect organisational outcomes (Leka \& Cox, 2008). Psychosocial risks refers to the potential of psychosocial hazards to cause harm and their magnitude will depend on several other issues, such as consensus in terms of their incidence and prevalence in the work environment, the particular groups they affect, and the measures taken to prevent them or alleviate their impact. Work-related stress is an outcome of exposure to psychosocial risks that has received a large amount of attention in the scientific literature.

Even though the majority of the literature focuses on measures that can be taken to address psychosocial risks (interventions) in order to alleviate negative outcomes (such as work-related stress) at the level of the organisation, the team, or the individual, a growing literature has been focussing on interventions that can be taken at the macro (international, regional, national or sectoral) level. With greater awareness of these types of risks and increasing evidence of their negative impact on individuals, organisations and society, came greater effort by policymakers to introduce interventions at the policy level (Leka et al., 2015).

The European Union (EU) is the region where the highest level of awareness raising efforts and interventions in relation to psychosocial risks have taken place including at the macro policy level. In fact, the policy context in relation to psychosocial risks in the EU is quite diverse and includes examples of various types of approaches implemented across countries and at national and regional level. However, it has been acknowledged that contrary to interventions at the individual and organisational level where many studies have been conducted to evaluate their outcomes, evaluation of policy-level interventions to address psychosocial risks is scarce (Leka et al., 2015).

This paper aims to address this gap by focussing on the case of one country in particular, Italy, where the policy context on psychosocial risks recently changed with the introduction of specific legislation on workrelated stress in 2008. Taking into consideration data collected through the European Survey of Enterprises on New and Emerging Risks (ESENER) immediately after (2009) and six years after (2014) the implementation of this new legislation,, this paper aims to explore whether Italian organisations report more action to address psychosocial risks after this policy level change. Since it is well known that the translation of policy into practice at the organisational level requires time (Leka \& Jain, 2013), the 2009 data is not expected to reflect organisational action due to the introduction of new legislation only a year earlier. However, this should be reflected in the 2014 data, especially since several actions were taken by the Italian government and its agencies to raise awareness and provide appropriate tools and support organisations in order to fulfil the new legal 
requirements. The following sections will first summarise the policy background on psychosocial risks in the EU and then discuss developments in Italy in order to contextualise these changes and their potential impact.

\section{The policy context on psychosocial risks in the European Union}

Psychosocial risks and their management are included in several types of policies in the EU, including binding legislation ('hard law'), and non-binding/voluntary policies ('soft law'). These types of policies have been developed both at EU level (being applicable to all EU member states) and at national member state level (that can be more specific and detailed than EU policies). At EU level, managing psychosocial risks is among employers' responsibilities as stipulated in the main occupational health and safety legislation in the EU - the Framework Directive 89/391/EEC on Safety and Health of Workers at Work - since it obliges employers to address all types of risk in a preventive manner and to establish health and safety procedures and systems to do so. It requires employers to adapt the work to the individual, especially as regards the design of workplaces, the choice of work equipment and the choice of working and production methods, with a view, in particular, to alleviating monotonous work and work at a predetermined work-rate. It also requires that employers developing a coherent overall prevention policy which covers technology, organization of work, working conditions, social relationships and the influence of factors related to the working environment.

However, there have been criticisms that even though the Directive asks employers to ensure workers' health and safety in every aspect related to work, 'addressing all types of risk at source', it does not include the terms 'psychosocial risk' or 'work-related stress', making understanding of its requirements by key stakeholders (e.g. employers) potentially unclear. This is also the case for the Directive on organisation of working time (93/104/EC), while the Council Directive on work with display screen equipment (90/270/EEC), actually refers to 'problems of mental stress' in the context of risk assessment. Leka et al. (2015) provide a review of key binding policies on psychosocial risks at EU level.

In addition to hard law, non-binding/voluntary policies have been developed in the form of recommendations, resolutions, opinions, proposals, conclusions of EU institutions (Commission, Council, Parliament), the Committee of the Regions and the European Economic and Social Committee. Furthermore, social partner agreements and frameworks of actions, specifications, guidance, campaigns etc. have been initiated by recognised European and international committees, agencies and organisations. Leka et al. (2015) also provide a review of key non-binding policies on psychosocial risks applicable at EU level. Among these policies, important developments have been the European social partner framework agreement on work-related stress (European Social Partners, 2004), and the framework agreement on harassment and violence at work (European Social Partners, 2007). These clarify the relevance of the Framework Directive 89/391/EEC on Safety and Health of Workers at Work to these issues and urge social partners in each EU member state to take action to address these issues collaboratively.

The European Commission has evaluated both the implementation of the Framework Directive and these two framework agreements. The Framework Directive evaluation (EC, 2004) indicated that long-term effects of 
risks that are not easily observed (e.g. on mental health) were being neglected in organisations' risk assessment and management actions, while there was also hardly any consideration of psychosocial risk factors. The findings of the evaluation indicated that much still needed to be done regarding psychosocial risks such as work control and work organisation, preventing unreasonably intense work pace and repetitive work. This suggested an insufficient application of some of the general principles of prevention foreseen in the Framework Directive 89/391 (Leka et al., 2014). As concerns the evaluation of the framework agreements for work-related stress and for harassment and violence at work, the main activities that followed the signing of the agreements were their translation in national languages (EC, 2011; European Social Partners, 2011) however they did act as catalysts for the implementation of new or updated legislation in some countries (e.g. the Czech Republic and Italy).

At national EU member state level (e.g. Sweden, Belgium, Italy, Germany, the Czech Republic), legislation is more specific than EU law and makes direct reference to work-related stress, bullying and harassment and/or psychosocial risks. In addition, good practice examples in this area exist in a number of member states, including the Management Standards in the UK and Italy, Work Positive in Ireland, the Work and Health Covenants and Catalogues in the Netherlands, ISTAS in Spain, SOBANE in Belgium, the tools developed by INRS and ANACT in France, and EU-OSHA's online simple risk assessment tool for SMEs, OiRA (Leka, Van Wassenhove \& Jain, 2015). The next section will focus on policy developments following the introduction of the framework agreement in work-related stress in one EU member state, Italy.

\section{Policy developments in relation to psychosocial risks in Italy}

In Italy, the term of work-related stress was introduced for the first time into the policy framework in June 2008, when the European Framework Agreement on work-related stress was translated in Italian and it was implemented into policy through the new updated normative framework concerning the health and safety at work, namely the Legislative Decree 81/2008 (Persechino et al., 2015). Before that, only general provisions without specific mention or examples of psychosocial risks were described into the national policies. Some references to the issues related to the organization of work may be found in the Italian civil code (1942), where in the article 2087 it is stated that "the employer is required to adopt, within his company's organization, the measures that, according to the particularity of the work, the experience and the technology, are necessary to protect the physical integrity and moral personality of the workers/employees". Although the European Framework Directive 89/391/EEC explicitly stated the obligation of employers to address and manage all types of risk in a preventive manner, the previous Italian normative framework on health and safety (Legislative Decree 626/1994) reported the obligation of evaluating all risks for workers' safety and health (implicitly including the psychosocial risks) only several years after its entry into force and under the pressure of a severe condemnation by the European Court of Justice (n. C - 49/00 of 15 November 2001). 
As mentioned above, under the pressure of the European Framework Agreement on work-related stress of 2004 an explicit reference to the protection of workers' health, also in relation to work-related stress, was made in the $\mathrm{LD} \mathrm{81/08}$ and its amendments and integrations for the first time. It states the obligation for employers to assess all risks for workers' health and safety, including risks associated with work-related stress, in accordance with the contents of the European Agreement. In addition, it adopts the World Health Organization's definition of health as "a state of complete physical, mental and social well-being and not merely the absence of disease or infirmity" that has certainly helped in focussing more on issues related to work-related stress within the Italian legislative framework (art. 3, par. 1, letter o) (Persechino et al., 2013). As regards its content, reference to work-related stress and its associated factors is found in two parts, one related to prevention activities and the other in relation to risk assessment. Regarding prevention activities, psychosocial factors are highlighted by art. 32, par. 2 stating that Workers' Representatives for Health need to be trained also about "risks associated to work-related stress".

However, the great advancement introduced by the LD 81/08 is related to risk assessment, stating that it must concern "all risks concerning health and safety of people at work, including those groups of workers exposed to particular risks, as well those risks associated with work-related stress, according to the European Agreement of 8 October 2004" (art. 28, par. 1) (Persechino et al., 2013). It is worth noting that the term psychosocial risks is not explicitly reported into the LD 81/08 but it refers to risks associated with work-related stress. Only in 2014, the term psychosocial risks appeared in the LD 19/2014 implementing the European Directive 2010/32/EU on prevention from sharp injuries in the hospital and healthcare sector. It states the obligation of the employer to "guarantee the workers' health and safety in all the aspects related to their professional life, including the psychosocial risks factors and the organization of work (art. 286-quarter).

Beyond stating the assessment of such risks, the LD 81/08 does not provide specific procedures to conduct it, leaving the role of providing guidelines to a Permanent Consultative Commission for Health and Safety at Work. Thus, a national debate flourished among social parties, institutions and national bodies on occupational health and safety to identify effective and sustainable solutions for supporting companies in the management of psychosocial risks. Then, in 2010 the guidelines by the Permanent Commission were published and established the following main criteria: 1) risks related to work-related stress must be assessed by the employer, in collaboration with OSH professionals and by involving employees and/or their representatives for health; 2) the assessment must focus not on individuals but on homogeneous groups of workers grouped on the basis of similar characteristics (such as their sex, age, nationality, type of contract, or any other working conditions); 3) the assessment is divided in two parts: the first one is called preliminary assessment (compulsory) where objective and verifiable outcomes and indicators of work-related stress are assessed (i.e. absence rate, turnover rates, content and context factors), while the second one is called in-depth assessment (potential) where perceptions of psychosocial risk factors are assessed. This methodological path represents the minimum level 
of implementation of the obligation, without precluding the possibility of a more articulated path based on specific needs and aspects related to the complexity of organisations (Persechino et al., 2013).

In line with these developments, the Italian Workers' Compensation Authority (INAIL) developed a methodology for the assessment and management of risks associated with work-related stress (Persechino et al., 2015) that resulted from a participative consultation process including occupational physicians, occupational psychologists, statisticians, national and international experts and stakeholders in occupational health. The aim was to develop an evidence-based and integrated methodological approach for supporting Italian companies in the management of risks associated with work-related stress aligned to the national legal requirements. This approach moves forward the minimum requirements by offering a dynamic continuous improvement methodological path based on the risk management framework. This methodology consists of four key phases and includes validated tools (Rondinone et al., 2014; Ronchetti et al., 2015) as well as the involvement of company OSH professionals and the active participation of workers right from the initial planning phase (Di Tecco et al., 2015). Offering tools that are scientifically valid and easy to use, the INAIL approach has now been implemented by a large number of Italian companies (more than 7,000) in the public and private sectors, and in many different fields of business (health, services, education, construction, etc.). Recently, through a project financed by the national Ministry of Health including 16 regions and two Universities, initiatives of INAIL have been focussed on offering evidence and findings useful in contributing to the update of the national policies on the management of psychosocial risks. Particularly, monitoring on how companies respond to the legal requirements for the management of work-related stress was conducted with a view of verifying the impact and adequacy of the provisions, including methods and tools offered to companies. Moreover, INAIL activities aimed to strengthen the link with labour inspection and OSH professionals to contribute in filling the gap between policy and practice and empowering competencies and skills for the effective management of risks associated to work-related stress.

Although at national level Italian legislation has a more specific focus than EU law with regard to work-related stress, there is no specific focus with regard to bullying and harassment. The Framework Agreement on Harassment and Violence at Work (European Social Partners, 2007) was only translated in Italian and signed by the national social parties in 2016. It calls for drawing up an internal agreement into companies on harassment and violence at work where preventive procedures and actions in adoption are reported. Real impacts of the national agreement, also at policy level, may be evaluated only in the next years.

One way to evaluate the impact of policy in practice is through the use of large scale, representative perception surveys at national, regional or sectorial level. This is discussed further in the next section and it is the methodology used in the current paper on the basis of an EU survey. 
The impact of public opinion on public policy is substantial and the salience of an issue enhances the impact of public opinion on policy development (Burstein, 2003). Perception surveys (also called public opinion/stakeholder surveys) are used for evaluating the success of regulatory reform programmes from a user's perspective and serve as a diagnostic tool, to identify areas of concern to business and citizens to inform future regulatory reforms. Perception surveys are also an integral part of a two-way communication strategy with stakeholders, as they serve as a means to communicate stakeholder views to the government, and as a basis for discussion between government and stakeholders on the case for regulatory reform. Survey results can also help to evaluate the success of the government's communication strategy by assessing stakeholders' level of awareness of recent initiatives (OECD, 2012).

A recent communication from the European Commission, calling for establishing a common framework for European statistics, emphasises the importance of reliable social statistics to monitor the social situation and the impact of policies on social conditions in EU Member States and their regions (EC, 2016). The Commission and its agencies have over the past decades developed several large scale surveys which contribute to the planning and establishment of better working conditions (e.g. the European Working Conditions Survey, European Labour Force Survey, European Survey of Enterprises on New and Emerging Risks). These surveys offer a unique source of comparative information on the quality of working conditions across the EU. Detailed analysis of the survey data allows stakeholders to identify new and emerging trends, as well as to gain deeper insight in the issues central to health and safety policy. The results provide a strong basis for policy makers to identify opportunities for improvement and to develop forward looking perspectives.

One such survey is the EU-OSHA's European survey of enterprises on new and emerging risks (ESENER), which explores the views of managers and workers' representatives on how health and safety risks are managed at their workplace (EU-OSHA, 2010, 2015). Questions cover management of health and safety in general, management of psychosocial risks, and worker participation. ESENER provides cross-nationally comparable information that can contribute to health and safety policy-making. The presence of two waves (the first one in 2009 and the second in 2014) along with its focus on new and emerging risks, with special reference to the management of psychosocial risks, also allow the analysis of possible developments in the management of psychosocial risks related to the implementation of policies both at European and national levels, particularly in those members states that have introduced specific legislation on psychosocial risks in recent years, like Italy.

This paper therefore aims to investigate the reported level of organisational action in the way psychosocial risks are managed in Italian establishments before and after the implementation of the European Framework Agreement on work-related stress into the national health and safety policy framework. It also aims to verify the impact of the introduction of provisions related to psychosocial risks into the Italian Legislative Decree 
81/08 and whether there has been any difference in how companies prioritise psychosocial issues in the workplace.

\section{Method}

Sample

The sample was extracted from the ESENER datasets, accessible to researchers via the United Kingdom Data Archive (UKDA) of the University of Essex. We included two ESENER waves. The first wave (ESENER-1) was carried out in 2009 and involved nearly 36,000 interviews among managers and OSH representatives. It covered all EU Member States as well as Turkey, Norway and Switzerland (31 countries). Private and public sector organisations with 10 or more employees were included in the interviews. This study took into account interviews conducted with managers. The second wave (ESENER-2) was carried out in 2014 and surveyed over 49,000 establishments in 36 countries. Five new countries - Albania, Iceland, the Former Yugoslav Republic of Macedonia, Montenegro and Serbia - were added to the 31 included in 2009. The following new features were introduced in the second wave of ESENER:

- $\quad$ The inclusion of smallest business size: 5 workers;

- The inclusion of the agriculture and fishing sector;

- A new target respondent: the person who knows most about safety and health at the workplace;

- $\quad$ An increased sample size by $50 \%$ with respect to ESENER-1.

Since micro enterprises (5 to 9 employees) were not included in ESENER-1, we decided to exclude them from 2014 respondents to allow a better comparison among data. Thus, the final sample was composed of 2,984 respondents corresponding to 1,501 in 2009 and 1,483 in 2014. ESENER data related to Italy that was used in the current study is summarized in Tables 1 and 2.

Table 1. ESENER data for Italy

\begin{tabular}{|c|c|c|}
\hline & 2009 & 2014 \\
\hline $\begin{array}{l}\text { Profile of the Italian } \\
\text { sample }\end{array}$ & $\begin{array}{r}300,000 \text { establishments } \\
11.2 \text { million workers } \\
\text { Smallest business size: } 10 \text { workers }\end{array}$ & $\begin{array}{r}\text { 674,000 establishments } \\
13.6 \text { million workers } \\
\text { Smallest business size: } 5 \text { workers }\end{array}$ \\
\hline Interviews & $\begin{array}{r}2,005 \text { interviews } \\
1,501 \text { managers } \\
504 \text { employee representatives }\end{array}$ & $\begin{array}{r}3,028 \text { interviews } \\
\text { person who knows most about safety and health } \\
\text { at the workplace } \\
1,483 \text { included (apart from micro enterprises) }\end{array}$ \\
\hline
\end{tabular}


Table 2. Sample distribution of organizational size in the two waves

\begin{tabular}{|c|c|c|c|c|c|c|}
\hline & & \multicolumn{4}{|c|}{ Organizational size } & \multirow[b]{2}{*}{ Total } \\
\hline & & $\begin{array}{r}5-9 \\
\text { emp }\end{array}$ & $\begin{array}{r}10-49 \\
\text { emp }\end{array}$ & $\begin{array}{r}50-249 \\
\text { emp }\end{array}$ & $\begin{array}{r}250+ \\
\text { emp }\end{array}$ & \\
\hline \multirow[t]{2}{*}{ Year } & 2009 & 0 & 2,208 & 345 & 40 & 2,593 \\
\hline & 2014 & $1,545^{*}$ & 1,244 & 216 & 23 & 3,028 \\
\hline Total & & 1,545 & 3,452 & 561 & 63 & 5,621 \\
\hline
\end{tabular}

\section{Measures}

ESENER data were collected though computer assisted telephone interviewing (CATI). According to the aims of the study, we selected items related to the management of psychosocial risks to provide a comparable analysis between 2009 and 2014. The following topics were included (see Table 3):

1. Occupational health and safety management: inclusion of an in-house or externally contracted psychologist involved in the management of health and safety services within the establishment; establishment of a documented policy on health and safety at work in the company;

2. Management of psychosocial risks: Level of concern about psychosocial risk factors, measures taken and procedures put in place.

All questions were measured as categorical variables $(1=\mathrm{yes} / 2=\mathrm{no})$.

Table 3. Selected items

\begin{tabular}{lr|r}
\hline & $\mathbf{2 0 0 9}$ & $\mathbf{2 0 1 4}$ \\
\hline Topic & Items & Items \\
\hline Health and safety management & MM150_3; MM155 & Q150_2; Q155 \\
\hline Management of psychosocial risks & MM202; MM250; MM251; MM252 & Q201; Q300; Q301; Q302 \\
\hline
\end{tabular}

\section{Data analysis}

As a first step, frequency analysis for Italy and the EU was conducted to provide an overview of the Italian findings in comparison to the EU in 2009 and 2014. Following this, a comparison between 2009 and 2014 Italian data was made by using chi square and estimating odds ratios (OR) and 95\% confidence intervals of the selected questions for the two survey waves.

According to EU-OSHA recommendations (EU-OSHA 2010, 2015), data comparing Italy and the EU was weighted to avoid any disproportionality of the Italian sample size in comparison with other EU countries. Italian data comparing 2009 and 2014 were weighted to adapt the actual structure of the Italian sample to the 
target structure of the Italian establishment population (EU-OSHA, 2015). Analyses were carried out with SPSS v.21.

\section{Results}

Most of the aspects investigated in this study showed improvements from 2009 and 2014 in Italy, with the exception being the use of a psychologist in health and safety management. In 2014, almost all Italian respondents reported to have a documented policy, established management system or action plan on health and safety in their establishments. This trend was also evident across the EU. Level of concern about psychosocial risk factors showed a small variation throughout the Europe, including Italy, with the exception of job insecurity, which was reported more frequently by Italian compared to European respondents. The level of concern for psychosocial risks was mixed, with concern for some risks showing a decrease in 2014. However, the provision and adoption of procedures to deal with work-related stress, bullying and harassment, and violence at work showed a general increase; particularly the use of procedures to deal with work-related stress in Italy was reported to be higher than the EU mean.

Table 4. Frequency analysis of study variables for Italy and the European Union in 2009 and 2014

\begin{tabular}{|c|c|c|c|c|}
\hline \multirow[b]{3}{*}{ Health and Safety Management } & \multicolumn{2}{|c|}{2009} & \multicolumn{2}{|c|}{2014} \\
\hline & IT & $\mathrm{EU}^{*}$ & IT & $\mathrm{EU}$ \\
\hline & & & & \\
\hline $\begin{array}{l}\text { Is there a documented policy, established management system or action plan on } \\
\text { health and safety in your establishment? }\end{array}$ & $83.1 \%$ & $76.1 \%$ & $98.3 \%$ & $90.7 \%$ \\
\hline $\begin{array}{l}\text { A psychologist - What health and safety services do you use, be it in-house or } \\
\text { contracted externally? }\end{array}$ & $14.9 \%$ & $16.4 \%$ & $10.2 \%$ & $16.7 \%$ \\
\hline
\end{tabular}

Level of concern about psychosocial risk factors

\begin{tabular}{|c|c|c|c|c|}
\hline Time pressure & $31.4 \%$ & $51.9 \%$ & $20.1 \%$ & $42.5 \%$ \\
\hline Poor communication between management and employees & $17.2 \%$ & $27.1 \%$ & $8.9 \%$ & $16.7 \%$ \\
\hline Lack of employee control in organising their work & $21.7 \%$ & $24.7 \%$ & $5.8 \%$ & $13.4 \%$ \\
\hline Job insecurity & $19.6 \%$ & $26.0 \%$ & $20.3 \%$ & $15.6 \%$ \\
\hline Having to deal with difficult customers, patients, pupils etc. & $34.5 \%$ & $49.8 \%$ & $36.7 \%$ & $57.4 \%$ \\
\hline Long or irregular working hours & $7.4 \%$ & $21.0 \%$ & $9.8 \%$ & $22.7 \%$ \\
\hline Discrimination (for example due to gender, age or ethnicity) & $1.5 \%$ & $6.0 \%$ & $0.8 \%$ & $2.2 \%$ \\
\hline
\end{tabular}

\begin{tabular}{lllll} 
Does your establishment have a procedure to deal with work-related stress? & $19.6 \%$ & $25.6 \%$ & $50.0 \%$ & $33.8 \%$ \\
\hline
\end{tabular}

\begin{tabular}{|c|c|c|}
\hline Is there a procedure in place to deal with bullying or harassment? & $9.4 \% \quad 29.7 \%$ & $31.8 \% \quad 47.4 \%$ \\
\hline
\end{tabular}

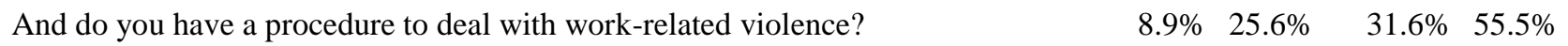

* The average for the EU includes data for Croatia although it was not a Member State of the EU in 2009 for the sake of consistency with the 2014 findings

(*) data weighted by adjusting for the disproportionality of the national sample sizes 
In depth comparisons among Italian responses in 2009 and 2014 are presented in Table 5. The level of concern about psychosocial risk factors showed a general significant decrease, with the exception of long irregular hours having a small significant increase. Although having to deal with difficult customers, patients, pupils showed an increase, no significant difference was found between 2009 and 2014.

On the other hand, there was a significant and positive difference in relation to the presence of a documented policy, established management system or an action plan on health and safety in establishments in 2014 (2009, $84.3 \% ; 2014,98.4 \% \mathrm{p}<.001)$ when almost all respondents answered positively. A great improvement was also found in 2014 with regard to the adoption of procedures to deal with work-related stress $(2009,19.8 \%$; 2014 , $43.2 \% ; \mathrm{p}<.001)$ as well as bullying and harassment $(2009,9.5 \% ; 2014,30.8 \%$; $<.001)$ and violence at work $(2009,9.0 \% ; 2014,30.7 \%$; $\mathrm{p}<.001)$. Thus, while a decreasing concern about psychosocial risks was reported over time, there was likely a corresponding improvement in the management of psychosocial risks, particularly as regards work-related stress prevention, showing a remarkable difference in how companies prioritise psychosocial issues in the workplace. As regards work-related stress, in the first wave, only $19.8 \%$ of companies reported having such procedures and Italy was quite below the EU mean with a marked lower percentage than those countries with the highest proportions (namely the United Kingdom and Ireland). However, in 2014 Italian enterprises reported higher percentages than the European mean. Although a significant increase was found also for bullying and harassment and violence at work in 2009 and 2014, Italian data remains below the EU mean. Finally, findings did not show any significant difference on the inclusion of an in-house or externally contracted psychologist in the establishment's health and safety services.

Table 5. Comparison of Italian data by year

\begin{tabular}{|c|c|c|c|c|c|c|}
\hline & \multicolumn{6}{|c|}{ Year of the survey } \\
\hline & \multirow[t]{2}{*}{2009} & \multirow[t]{2}{*}{2014} & \multirow{2}{*}{$\begin{array}{c}X^{2} \\
(1 \text { d.f. })\end{array}$} & \multirow[t]{2}{*}{ Odds Ratio } & \multicolumn{2}{|c|}{$95 \% \mathrm{CI}$} \\
\hline & & & & & Lower & Upper \\
\hline $\begin{array}{l}\text { Is there a documented policy, } \\
\text { established management system or } \\
\text { action plan on health and safety in } \\
\text { your establishment? }\end{array}$ & $84.3 \%$ & $98.4 \%$ & $196.913 * *$ & 11.29 & 7.44 & 17.14 \\
\hline $\begin{array}{l}\text { A psychologist - What health and } \\
\text { safety services do you use, be it in- } \\
\text { house or contracted externally? }\end{array}$ & $15.0 \%$ & $12.9 \%$ & 3.554 & .84 & .69 & 1.01 \\
\hline Time pressure & $31.8 \%$ & $19.8 \%$ & $67.328 * *$ & .53 & .45 & .62 \\
\hline $\begin{array}{l}\text { Poor communication between } \\
\text { management and employees }\end{array}$ & $17.4 \%$ & $9.9 \%$ & $41.393 * *$ & .52 & .43 & .64 \\
\hline $\begin{array}{l}\text { Lack of employee control in } \\
\text { organising their work }\end{array}$ & $14.8 \%$ & $9.1 \%$ & $27.628 * *$ & .57 & .47 & .71 \\
\hline Job insecurity & $19.9 \%$ & $17.0 \%$ & $5.141 *$ & .82 & .70 & .97 \\
\hline
\end{tabular}




\begin{tabular}{|c|c|c|c|c|c|c|}
\hline $\begin{array}{l}\text { Having to deal with difficult } \\
\text { customers, patients, pupils etc. }\end{array}$ & $34.8 \%$ & $37.2 \%$ & 2.453 & 1.11 & .97 & 1.27 \\
\hline Long or irregular working hours & $7.5 \%$ & $10.0 \%$ & $7.718 * *$ & 1.37 & 1.09 & 1.72 \\
\hline $\begin{array}{l}\text { Discrimination (for example due to } \\
\text { gender, age or ethnicity) }\end{array}$ & $1.5 \%$ & $.07 \%$ & $4.165^{*}$ & .50 & .26 & .99 \\
\hline $\begin{array}{l}\text { Does your establishment have a } \\
\text { procedure to deal with work-related } \\
\text { stress? }\end{array}$ & $19.8 \%$ & $43.2 \%$ & $189.505 * *$ & 3.07 & 2.61 & 3.61 \\
\hline $\begin{array}{l}\text { Is there a procedure in place to deal } \\
\text { with bullying or harassment? }\end{array}$ & $9.5 \%$ & $30.8 \%$ & $235.343 * *$ & 4.22 & 3.48 & 5.13 \\
\hline $\begin{array}{l}\text { And do you have a procedure to deal } \\
\text { with work-related violence? }\end{array}$ & $9.0 \%$ & $32.7 \%$ & $163.249 * *$ & 4.92 & 3.78 & 6.40 \\
\hline
\end{tabular}

Note: $N=2.984 ; * * p<.001 * p<.05$. Data weighted according to the structure of the population of the Italian establishments

\section{Discussion}

The aim of this paper was to investigate the level of organisational action in the way psychosocial risks are managed in Italian establishments before and after the implementation of specific legislation on work-related stress in 2008. Moreover, this paper verified whether there has been any difference in how companies prioritise psychosocial issues in the workplace. Using representative data at European level through ESENER, our analysis identified differences in the reported level of organisational action immediately after and six years after the implementation of this new legislation. In particular, more than double the number of enterprises reported having a procedure in place to deal with work-related stress in 2014 in comparison to 2009, while more than triple the number of enterprises reported having a procedure in place to deal with harassment or bullying, and with work-related violence. When comparing these results with those reported overall in Europe, it can be observed that more enterprises specifically report having in place a procedure to deal with workrelated stress in Italy while findings for harassment and bullying, and for work-related violence are comparable to European data. Furthermore, the use of a psychologist was not reported to increase in Italy but rather decreased although there was no significant difference between Italian and European data. Finally, concern for most psychosocial risk factors, did not increase in 2014 in comparison to 2009.

Overall these findings provide mixed results in relation to the potential impact of the introduction of new legislation on work-related stress in Italy. While more action is being reported by Italian enterprises as concerns having a procedure in place to deal with work-related stress, this does not apply in the same way as concerns psychosocial risks in general. This might be because the term psychosocial risks is not included in the new legislation which raises the issue of understanding in this area due to lack of clear terminology used in various pieces of legislation applicable to the EU overall, and in that of specific countries. As scholars have highlighted, lack of harmonised terminology hinders understanding of key stakeholders, including employers 
and has an impact on organisational action (Ertel et al., 2010; Leka et al., 2015). These findings were also confirmed in a recent Italian survey (INAIL, 2014) where higher levels of concern were found for work-related stress compared to psychosocial risk factors among workers.

The increased reported importance in prioritising work-related stress in Italy from 2009 to 2014 could be related to the developments at the national policy level in this area that have led to an increase in the level of awareness among stakeholders. Already 16 years ago, work-related stress was a priority for workers' health and safety among occupational safety and health specialists and stakeholders (Iavicoli et al., 2001). Nevertheless, it remained for several years only a research priority without translating solutions into practice. The path taken in the following decade at policy level with the implementation of specific legislation may have contributed to overcoming this existing gap. The important role of policies, and especially legislation, in increasing awareness and driving action has been acknowledged in the literature (Leka et al., 2010). The reported increased level of awareness and action could also be related to national initiatives, such as those promoted by INAIL, which aimed to disseminate tools and guidance, to empower competencies of OSH professionals and to offer solutions tailored to establishments' specific needs in order to manage risks associated to work-related stress more effectively. Currently, more than 7,000 companies are using INAIL's methodology that is accessible through an online web platform. Moreover, recent monitoring conducted by the national labour inspectors highlighted that out of 801 companies monitored, the majority have used INAIL's methodology for the assessment and management of work-related stress. It is therefore important to continue to disseminate information and tools on psychosocial risk factors with a view of boosting awareness of these issues and their effects on workers' health as well as on organizational performance and company productivity.

Differences in prioritisation of psychosocial risks have also been attributed to a lack of expertise, supporting infrastructure and cultural variations across EU countries (Leka et al., 2010). In this regard, it should be noted that in Italy occupational health psychology (OHP) has not developed as in other countries in Europe and the USA. There are several professional specialisations in Italy concerning health and work, which may contribute to addressing occupational health issues: occupational medicine, work and organizational psychology, social psychology, health psychology, psychometrics. OHP is a focused specialisation recognizing the multidisciplinary nature of occupational health. It converges and integrates knowledge, insights, methods and frameworks from a diverse number of specialisations related to occupational health (Cox et al., 2000). Although the Italian normative framework gives great importance to the role of OSH professionals in addressing and managing risks associated with work-related stress, the findings of this study showed that the inclusion of an in-house or contracted externally psychologist in the establishment's health and safety services remained low over time. Effective OSH management depends on the availability of expertise and competencies in relation to OSH issues (EU-OSHA, 2010), thus there is a primary need of expanding the skills and knowledge of managers, supervisors and occupational health and safety practitioners in psychosocial risk management in order to integrate the management of psychosocial risks into health and safety management. Moreover, the involvement of specialist expertise (for example from a psychologist), particularly when already 
available in organisations, may be helpful in carrying out an effective risk assessment, and importantly in supporting the development of effective interventions and actions, alongside with other OSH professionals. Initiatives at policy level should also place emphasis not only on increasing awareness but also on improving knowledge and skills in company OSH services where needed.

Finally, it should be acknowledged that the use of surveys such as ESENER, that provide representative data in various waves, is an important tool in evaluating trends over time, in this case in relation to occupational health and safety management, in European enterprises. Supplementing such analysis with data collected at national level, as in the case of Italy, is invaluable and can contribute to a fuller evaluation of the picture in various countries with a view to improvement actions being taken and lessons learned across Europe. This is particularly important, since efforts should be made to cross-fertilise knowledge and use available resources wisely to achieve the ambitious goals set by European strategies and policies (Iavicoli et al., 2014).

A limitation that needs to be considered in relation to the current study is the possible impact of social desirability (Fisher, 1993) on the survey responses, especially since many of the survey respondents were managers. In addition, the study was cross-sectional so no causality can be inferred. A longitudinal study would allow for more reliable conclusions to be drawn. However, it is encouraging to note that a recent national Italian survey has confirmed some of the study results. Nonetheless, the study used two very sizeable representative datasets across Europe which allowed comparisons both within Italy and with other European countries. In this respect, the current study has made a significant contribution to the literature by showing that Italian organisations report more action to address psychosocial risks after the introduction of specific legislation on work-related stress.

\section{Acknowledgement:}

The authors are grateful to the European Agency for Safety and Health at Work (EU-OSHA), and the UK Data Archive for access to the ESENER datasets. The interpretation of the data presented in this paper is that of the authors.

\section{References}

Burstein, P. (2003). The impact of public opinion on public policy: A review and an agenda. Political Research Quarterly, 56, 29-40.

Cox, T., Dewe, P., Nielsen, K., \& Cox, R. (2000). Occupational Health Psychology: Europe 2000. Nottingham: IWHO Publications. 
Di Tecco, C., Ronchetti, M., Ghelli M., Russo S., Persechino, B., \& Iavicoli, S. (2015). Do Italian companies manage work-related stress effectively? A process evaluation in implementing the INAIL methodology. BioMed Research International, vol. 2015, Article ID 197156. doi:10.1155/2015/197156.

Ertel, M., Stilijanow, U., Iavicoli, S., Natali, E., Jain, A., Leka, S. (2010). European social dialogue on psychosocial risks at work: Benefits and challenges. European Journal of Industrial Relations, 16(2), 169-183. European Social Partners (2004). Framework agreement on work-related stress. European social partners ETUC, UNICE(BUSINESSEUROPE), UEAPME and CEEP, Brussels.

European Social Partners (2007). Framework agreement on harassment and violence at work. European social partners - ETUC, BUSINESSEUROPE, UEAPME and CEEP, Brussels.

European Social Partners (2011). Implementation of the European autonomous framework agreement on harassment and violence at work - Final joint report by the European Social Partners. Brussels: European social partners - ETUC, BUSINESSEUROPE, UEAPME and CEEP.

EC - European Commission (2004). Communication from the Commission to the European Parliament, the Council, the European Economic and Social Committee and the Committee of Regions on the practical implementation of the provisions of the Health and Safety at Work Directives 89/391 (Framework), 89/654 (Workplaces), 89/655 (Work Equipment), 89/656 (Personal Protective Equipment), 90/269 (Manual Handling of Loads) and 90/270 (Display Screen Equipment). COM/2004/0062 final. Luxembourg: Office for Official Publications of the European Communities.

European Commission (EC) (2011). Report on the implementation of the European social partners Framework Agreement on Work-related Stress. SEC(2011) 241 final, Commission staff working paper, Brussels.

European Commission (EC) (2016). Proposal for a regulation of the European parliament and of the council establishing a common framework for European statistics relating to persons and households, based on data at individual level collected from samples. COM(2016) 551 final. Brussels: European Commission.

EU-OSHA (2010). European Survey of Enterprises on New and Emerging Risks - Managing safety and health at work. Luxembourg: Publications Office of the European Union.

EU-OSHA (2015). European Survey of Enterprises on New and Emerging Risks - Managing safety and health at work. Luxembourg: Publications Office of the European Union.

Filer, R.K., \& Golbe, D.L. (2003). Debt, operating margin, and investment in workplace safety. Journal of Industrial Economics, 51, 359-381.

Iavicoli, S. Marinaccio, A., Vonesch, N., Ursini, C.L., Grandi, C., Palmi C. (2001). Research priorities in occupational health in Italy. Occupational Environmental Medicine, 58, 325-329. 
Iavicoli, S., Leka, S., Jain, A., Persechino, B., Rondinone, B.M., Ronchetti, M., \& Valenti, A. (2014). Hard and soft law approaches to addressing psychosocial risks in Europe: Lessons learned in the development of the Italian approach. Journal of Risk Research, 17(7), 855-869.

INAIL (2014) Indagine nazionale sulla salute e sicurezza sul lavoro. Tipografia Milano: INAIL.

Leka, S., \& Cox, T. (2008). PRIMA-EF Guidance on the European Framework for Psychosocial Risk Management: A resource for employers and worker representatives (WHO Protecting Workers' Health series, number 9). WHO: Geneva.

Leka, S., \& Jain, A. (2013). The policy context to occupational and organisational health research. In G. Bauer \& O. Hamming (Eds.), Bridging Occupational, Organisational \& Public Health. The Netherlands: Springer.

Leka, S., Jain, A., Iavicoli, S., \& Di Tecco, C. (2015). An evaluation of the policy context on psychosocial risks and mental health in the workplace in the European Union: Achievements, challenges and the future. BioMed Research International, Special issue on Psychosocial Factors and Workers' Health \& Safety. http://dx.doi.org/10.1155/2015/213089

Leka, S., Jain, A., Iavicoli, S., Vartia, M., Ertel, M. (2010). The role of policy for the management of psychosocial risks at the workplace in the European Union. Safety Science, 49, 558-564.

Leka, S., Van Wassenhove, W., \& Jain, A. (2015). Is psychosocial risk prevention possible? Deconstructing common presumptions. Safety Science, 71(1), 61-67.OECD (2012). Policy lessons for the use of perception surveys for evaluation, diagnosis and communication. In: Measuring Regulatory Performance: A Practitioner's Guide to Perception Surveys. Paris: OECD Publishing. Available at: http://dx.doi.org/10.1787/9789264167179-8-en

Persechino, B., Valenti, A., Ronchetti, M., \& Iavicoli, S. (2015). La legislazione italiana in tema di stress lavoro-correlate. Quaderni di Medicina del Lavoro Ergonomia e Terapia Occupazionale, 4, 23-30.

Persechino, B., Valenti, A., Ronchetti, M., Rondinone, B.M., Di Tecco, C., Vitali, S., \& Iavicoli. S. (2013) Work related stress risk assessment in Italy: a methodological proposal adapted to regulatory guidelines, Safety and Health at Work, 4(2), 95-99.

Ronchetti, M., Di Tecco, C., Russo, S., Castaldi, T., Vitali, S., Autieri, S., Valenti, A., Persechino, B., \& Iavicoli, S. (2015). An integrated approach to the assessment of work-related stress risk: Comparison of findings from two tools in an Italian methodology. Safety Science, 80, 310-316. doi: 10.1016/j.ssci.2015.08.005.

Rondinone, B.M., Persechino, B., Castaldi, T., Valenti, A., Ferrante, P., Ronchetti, M., \& Iavicoli, S. (2012). Work related stress risk assessment in Italy: the validation study of Health Safety and Executive Indicator Tool. Giornale Italiano di Medicina del Lavoro ed Ergonomia, 34(4), 392-9. 